Article

\title{
Selective Liberation of High-Phosphorous Oolitic Hematite Assisted by Microwave Processing and Acid Leaching
}

\author{
Xianyan Cai ${ }^{1,2}$, Gongming Qian ${ }^{1,2}{ }^{*} \mathbb{E}$, Bo Zhang ${ }^{1}$, Qiushi Chen ${ }^{1}$ and Chenqiang $\mathrm{Hu}^{1}$ \\ 1 College of Resources and Environmental Engineering, Wuhan University of Science and Technology, \\ Wuhan 430081, China; xianyancaiyaaa@126.com (X.C.); 18171296604@163.com (B.Z.); \\ 15972923255@163.com (Q.C.); 15671550957@163.com (C.H.) \\ 2 Hubei Key Laboratory for Efficient Utilization and Agglomeration of Metallurgic Mineral Resources, \\ Wuhan University of Science and Technology, Wuhan 430081, China \\ * Correspondence: qiangongming@wust.edu.cn; Tel.: +86-134-7683-4865
}

Received: 12 April 2018; Accepted: 29 May 2018; Published: 7 June 2018

\begin{abstract}
The release of valuable minerals from the associated gangues is called liberation. Good liberation is essential to the subsequent separation stage. Selective liberation is advantageous to improve the degree of liberation. Oolitic hematite is one of the typical refractory iron ores in China, and its resources are abundant. However, owing to its fine dissemination and complex mineralogical texture, the conventional grinding processes are inefficient in improving the selective liberation of oolitic hematite. In this study, microwave processing and acid leaching were used to assist the liberation of oolitic hematite. The assisted liberation of the oolitic hematite mechanisms of microwave processing and acid leaching were studied by using scanning electron microscope (SEM), X-ray diffraction (XRD), BET specific surface area detection method (BET) and the transflective microscope method. The results indicated that microwave processing can reduce the mechanical strength of oolitic hematite and improve the liberation of hematite, and acid leaching can improve the microwave-assisted liberation efficiency and reduce the content of phosphorus in the grinding product. Compared to direct grinding, the liberation of hematite increased by $54.80 \%$ in the grinding product, and especially, the fractions of $-0.038-\mathrm{mm}$ and $0.05-0.074 \mathrm{~mm}$ increased significantly; however, there was no obvious change in other grain sizes, and the dephosphorization ratio reached $47.20 \%$ after microwave processing and acid leaching. After the two stages, the iron grade and recovery of the magnetic separation product increased by $14.26 \%$ and $34.62 \%$, respectively, and the dephosphorization ratio reached $88.59 \%$. It is demonstrated that microwave processing and acid leaching comprise an efficient method to improve the liberation of hematite and the dephosphorization ratio of oolitic hematite. The two-stage treatment can achieve selective liberation of oolitic hematite, which is beneficial to the following magnetic separation.
\end{abstract}

Keywords: oolitic hematite; microwave; acid leaching; selective liberation; dephosphorization

\section{Introduction}

As a typical refractory iron ore, high-phosphorus oolitic hematite is distributed widely and is an abundant resource worldwide. There are approximately 30-40 billion tons of high-phosphorus oolitic hematite ores in China, but commercial exploitation and utilization have not been achieved [1-4]. The reason why is that the complex structure and fine-grained dissemination of oolitic hematite make it very difficult to liberate [5].

It is well known that good liberation is the basis of beneficiation. Therefore, mineral liberation has stimulated great interest in the field of mineral processing, especially in complex minerals' 
separation [6]. Size reduction is an important method of liberating valuable minerals from their associated gangues $[7,8]$. However, the degree of liberation is a more important indicator than size reduction when characterizing the liberation in mineral processing [9]. A perfect liberation forms fractures along the grain boundary of the valuable mineral and gangues, which is described as selective liberation. If selective liberation is achieved, the subsequent separation stage would become easier and more economical. For instance, Fandrich et al. reported that non-random breakage was advantageous to the improvement of iron oxide liberation [10]. Wang et al. found that the electrical comminution product was better liberated than in the conventional comminution, and that the process made the next stage consuming less energy [11].

In the literature, a number of methods have reportedly been able to improve the degree of liberation, such as heating treatment, adding grinding acid in the grinding process, electrical comminution, and so on. As a physical treatment method to improve the liberation of minerals, microwave processing has been one of the recent hotspots in minerals' processing [12-14]. For example, microwaves can make copper minerals better liberated at a coarse particle size [15]. Amankwah used microwave processing to treat gold ore, which increased the liberation of gold, and gold recovery improved from about $28 \%-40 \%$ [16].

High-phosphorus oolitic hematite is usually associated with hematite, carbonate-hydroxyapatite, quartz and chamosite, which have different abilities in absorbing microwave energy and dielectric properties [17]. Hematite has a good ability to absorb microwave energy, so it has a rapid temperature rise during microwave processing, whereas the gangue has a weak ability to absorb microwave energy and has almost no change in temperature. Therefore, a huge temperature difference between hematite and gangues occurs. Thermal expansion properties of differ between minerals. Therefore, grain boundaries between hematite and gangue squeeze each other and generate thermal stress. When the thermal stress reaches a certain level, fractures appear at the boundaries. This can improve the ratio of selective liberation and aid in increasing the grinding efficiency [18-20]. Therefore, microwave processing can enhance the liberation of the high-phosphorus oolitic hematite by generating grain boundary fractures in oolitic iron ore. For instance, Walkiewicz et al. reported that the ore can be quickly heated to $840-940{ }^{\circ} \mathrm{C}$ at a microwave power of $3 \mathrm{~kW}$, and fractures formed along grain boundary [21]. Orman et al. investigated the effects of microwave processing and the conventional heating pretreatment on the liberation of oolitic iron. SEM images illustrated that intergranular fractures were generated between gangue minerals and hematite after microwave treatment, but only a small quantity of fractures were generated by the conventional heating treatment [22]. However, there is no detailed data for the analysis of the influence of microwave processing on improving the liberation and the effect for the following separation.

Microwaves processing is also beneficial for the dephosphorization of oolitic hematite. For instance, He et al. investigated the effect of microwave processing on the dephosphorization of high-phosphorus hematite. The result indicated that microwave treatment strengthened the effect of carbothermal reduction on dephosphorization and increased iron content [23]. Omran et al. studied the effect of combined microwave pretreatment and ultrasonic treatment on the efficiency of dephosphorization. The results indicated that intergranular fractures between the hematite and gangues in the ore were generated after microwave treatment. These intergranular fractures accelerated the removal of phosphorus and gangue minerals from oolitic hematite in ultrasonic processing [24].

When acid is added to the samples which have been treated by microwaves, the acid can easily enter the intergranular fractures, facilitating the generation of fractures and dissolving the gangue containing phosphorus. Therefore, acid leaching can improve the efficiency of microwave-assisted grinding and reduce the content of phosphorus in the grinding product.

Zhong et al. investigated the effect of acid leaching on a high-phosphorus iron ore concentration after magnetic roasting and separation. It was found that the phosphorus content was reduced from $0.83 \%-0.24 \%$, while the recovery of iron increased steadily, from a minimum of $91.89 \%$ to a maximum 
of $95.50 \%$. The result indicated that acid leaching was an efficient method to decrease the content of phosphorus of iron ore, but would not reduce the recovery of iron mineral [25].

In this study, microwave processing and acid leaching were applied to improve the liberation of oolitic hematite, and the effect of the method on grinding, liberation, the dephosphorization ratio of oolitic hematite and the following magnetic separation was investigated.

\section{Materials and Methods}

\subsection{Materials}

Oolitic hematite ore was collected from the western part of Hubei Province, China. The chemical composition, iron phase and phosphorus phase of this ore are presented in Tables 1 and 2, respectively. The total Fe and phosphorus grade were $43.31 \%$ and $1.49 \%$, respectively. The main valuable mineral was hematite, which was $95.91 \%$ iron in the ore. The main gangue minerals were quartz, carbonate-hydroxyapatite and chamosite. The phosphorus was mainly distributed in carbonate-hydroxyapatite. The optical micrograph and SEM of oolitic hematite are described in Figure 1. The images show that oolitic hematite was composed of ooid grains and matrix (mainly hematite, quartz and chamosite), and the ooid was composed of several concentric layers of iron minerals and gangue.

Table 1. Raw ore chemical composition (wt \%).

\begin{tabular}{cccccccccc}
\hline Formula & $\mathbf{T F e}$ & $\mathrm{SiO}_{2}$ & $\mathrm{Al}_{2} \mathbf{O}_{3}$ & $\mathbf{C a O}$ & $\mathbf{M g O}$ & $\mathbf{M n O}$ & $\mathbf{K}_{\mathbf{2}} \mathbf{O}$ & $\mathbf{P}_{2} \mathbf{O}_{5}$ & $\mathbf{S}$ \\
\hline Weight $\%$ & 43.31 & 20.44 & 6.89 & 3.91 & 1.28 & 0.11 & 0.39 & 3.41 & 0.03 \\
\hline
\end{tabular}

Table 2. Iron and phosphorus content of oolitic hematite.

\begin{tabular}{cccc}
\hline Element & Phase & wt \% & Distribution Rate (\%) \\
\hline \multirow{4}{*}{$\mathrm{Fe}$} & Magnetite & 0.31 & 0.72 \\
& Hematite & 41.54 & 95.91 \\
& Iron carbonate & 0.13 & 0.30 \\
& Iron sulfide & 0.06 & 0.14 \\
$\mathrm{P}$ & Ferric silicate & 1.27 & 2.39 \\
\hline \multirow{3}{*}{} & Carbonate-hydroxyapatite & 0.31 & 87.74 \\
& Hematite/goethite & 41.54 & 7.11 \\
& Ferric silicate & 0.13 & 2.30 \\
& Other mineral & 0.06 & 1.86 \\
\hline
\end{tabular}
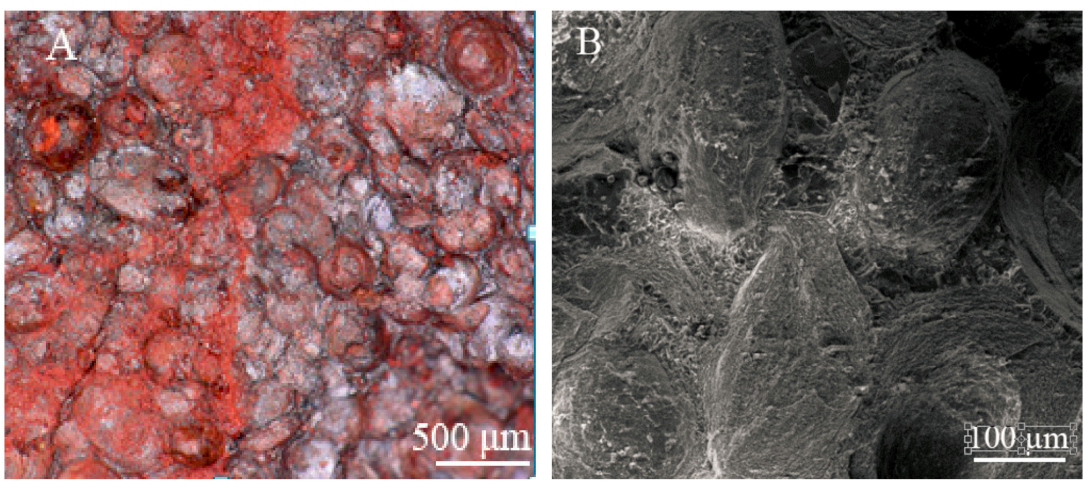

Figure 1. Oolitic hematite. (A) optical micrograph; (B) SEM image. 


\subsection{Methods}

\subsubsection{Basic Test Flowchart}

First, raw ore was treated by coarse crushing. Next, part of the sample was treated by fine crushing, grinding and magnetic separation. Another part of the sample was treated by microwave processing, water quenching and fine crushing to get the sample $(-2 \mathrm{~mm})$. Then, part of the sample $(-2 \mathrm{~mm}$, treated by microwave processing) was treated by grinding and magnetic separation. Another part of the sample ( $-2 \mathrm{~mm}$, treated by microwave processing) was treated by acid leaching, water washing, grinding and magnetic separation. The basic test flowchart is shown in Figure 2.

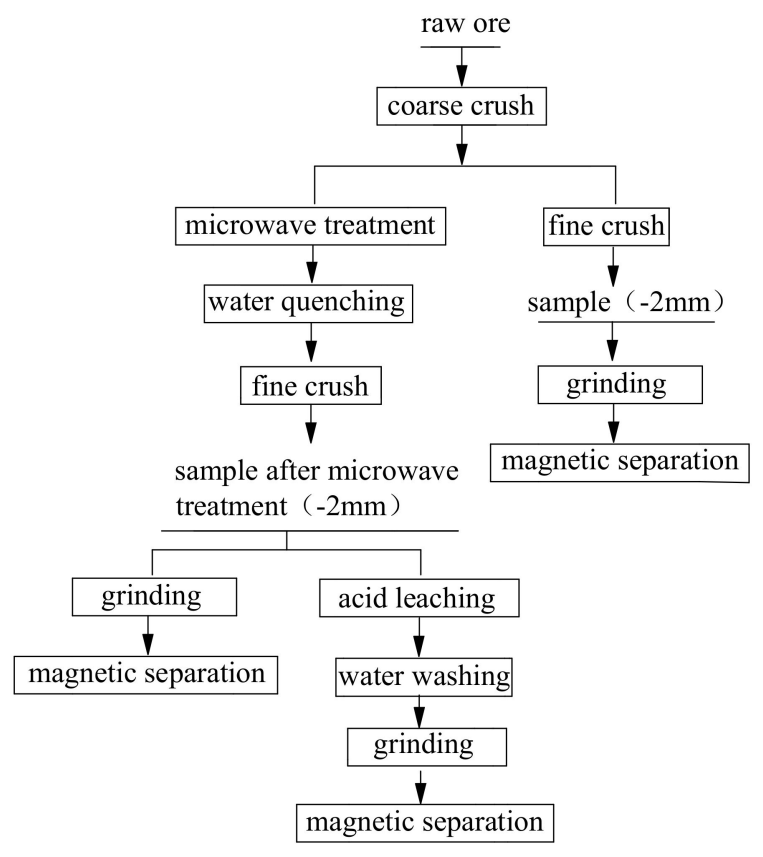

Figure 2. The basic flowchart of the experiment.

\subsubsection{Iron ore Pretreatment}

Since the size of the selected ore was uneven, it should be pre-crushed and screened to obtain 10-15-mm grain size. Water has good absorption of microwave radiation, and the dielectric properties of water are related to the microwave frequency and material temperature. In order to avoid the water affecting the ore on the absorption of microwave energy and the heating rate of iron mineral, the ore was dried until the water evaporated entirely in the sample before microwave processing.

\subsubsection{Microwave Processing and Grinding Experiment}

A microwave oven (HAMiLab-V3000, Longtai microwave thermal industry Co., Ltd., Changsha, China) was used in microwave processing. A series of microwave processing times $(0,15$, $30,45,60$ and $75 \mathrm{~s})$ at a microwave power of $2.5 \mathrm{~kW}$ and microwave powers $(1,1.5,2,2.5,3,3.5,4$ $\mathrm{kW}$ ) at a microwave processing time of $45 \mathrm{~s}$ were applied to investigate the effect of microwave power and microwave processing time on the grinding and liberation of oolitic hematite. The weight of the ore was $100 \mathrm{~g}$ every time in the microwave processing. A conical ball mill (XMQ-ical $\times 90$, Wuhan exploring machinery factory, Wuhan, China) operating at a filling rate of $35 \%$ and a mill rotation of $70 \mathrm{rpm}$ was used in the grinding, at the grinding conditions at a time of $9 \mathrm{~min}$, a pulp density of 50\% and a processing capacity of $200 \mathrm{~g}$ every time. 


\subsubsection{Acid Leaching Experiment}

The ore used in the acid leaching experiment had been pretreated by microwave processing $(2.5 \mathrm{~kW}, 45 \mathrm{~s})$. First, the ore was leached by concentrated hydrochloric acid (liquid-solid ratio 1:1). Then, the ore was washed to remove acid, and the grinding experiment was performed using the conical ball mill. In the experiments, different acid dosages (mass ratios) $(1,2,3,4,5,6,7,8,9,10 \%)$ at an acid leaching time of $50 \mathrm{~min}$ and acid leaching times (10, 20, 30, 40, 50, 60, $80 \mathrm{~min}$ ) at an acid dosage of $5 \%$ were applied to investigate the effect on the grinding, the liberation of hematite and the dephosphorization ratio of high-phosphorus oolitic hematite.

\subsubsection{Magnetic Separation Experiment}

A SLon-100 periodic pulsating high gradient magnetic separator with a pulse frequency of $45 \mathrm{MHz}$ was used in the magnetic separation experiment. Three respective samples with different treatment conditions (direct grinding, microwave processing, microwave processing and acid leaching) were used in the experiment at a magnetic intensity of $900 \mathrm{kA} / \mathrm{m}$. Direct grinding means ore treated by grinding without the treatment of microwave processing and acid leaching.

\subsubsection{Analytical Techniques}

The micro-morphological characteristics of the samples at different microwave processing conditions were investigated by a Zeiss ULTRA plus field emission scanning electron microscope (Jeol Ltd., Tokyo, Japan) (SEM). Raw ore and ore after microwave processing and acid leaching were ground under the same conditions, and X-ray diffraction (Rigaku Ltd., Tokyo, Japan) was adapted to analyze the mineralogical composition. The degree of hematite liberation of three different grinding products (direct grinding, microwave processing and microwave processing and acid leaching) was investigated by an XPV-201 Series Transflective Polarizing Microscope (Shanghai Changfang optical instrument Co., Ltd., Shanghai, China) with the area method. The specific surface area and porosity of the ore samples before and after microwave processing were analyzed by the BET method. The grindability test was conducted by a power index ball mill (XMGQ) with the dry closed-circuit grinding method. The standard Bond work index was calculated using the data at $250 \%$ of the grinding cycle load from the following Equation (1) [26]. The calculation method of the dephosphorization ratio was as Equation (2).

$$
W_{i}=\frac{4.906}{P_{i}^{0.23} \cdot G_{b g}^{0.82}\left(\frac{1}{\sqrt{P_{80}}}-\frac{1}{\sqrt{F_{80}}}\right)}
$$

In the equation:

$\mathrm{W}_{i}$, ball mill work index, $\mathrm{kW} \cdot \mathrm{h} / \mathrm{t}$;

$P_{i}$, screen size, $\mu \mathrm{m}$;

$G_{b g}$, net weight of the ball mill product passing sieve size $P_{\text {i }}$ produced per mill revolution, $\mathrm{g} / \mathrm{r}$;

$P_{80}$, sieve opening through which $80 \%$ of the product passes, $\mu \mathrm{m}$;

$F_{80}$, sieve opening through which $80 \%$ of the product passes, $\mu \mathrm{m}$;

$$
\mu=\frac{p_{0}-p_{1}}{p_{0}} \times 100 \%
$$

In the equation:

$\mu$, the dephosphorization ratio, $\%$;

$p_{0}$, the content of phosphorus before grinding, \%;

$p_{1}$, the content of phosphorus after grinding, $\%$. 


\section{Results and Discussion}

\subsection{The Effect of Microwave Processing on the Ore and Grinding}

To understand the mechanism of microwave processing, the physical properties of the ore before and after microwave processing were studied (Table 3). Table 3 shows that the specific surface and porosity increased, and the compressive strength and the ball mill work index of the ores decreased after microwave processing. The change of parameters in the four properties made the ore's grindability increase. The SEM images of the ore after being treated at different microwave processing conditions are shown in Figure 3. The images show that there were fractures generated after microwave processing, and the number of fractures was largest at a microwave power of $2.5 \mathrm{~kW}$ and a microwave processing time of $45 \mathrm{~s}$. The fractures increased the ore's grindability.

Table 3. Parameters in four properties of raw ore and ore after microwave.

\begin{tabular}{|c|c|c|c|c|}
\hline $\begin{array}{c}\text { Microwave } \\
\text { Processing Condition }\end{array}$ & $\begin{array}{l}\text { Specific Surface Area } \\
\left(\mathrm{m}^{2} / \mathrm{g}\right)\end{array}$ & $\begin{array}{c}\text { Compressive Strength } \\
\left(\mathrm{N} / \mathrm{cm}^{2}\right)\end{array}$ & $\begin{array}{l}\text { Porosity } \\
(\%)\end{array}$ & $\begin{array}{l}\text { Ball Mill Work Index } \\
(\mathrm{kW} \cdot \mathrm{h} / \mathrm{t})\end{array}$ \\
\hline raw ore & 8.74 & 1.93 & 4.14 & 15.25 \\
\hline $2.5 \mathrm{~kW}, 45 \mathrm{~s}$ & 13.28 & 0.39 & 5.79 & 10.11 \\
\hline
\end{tabular}
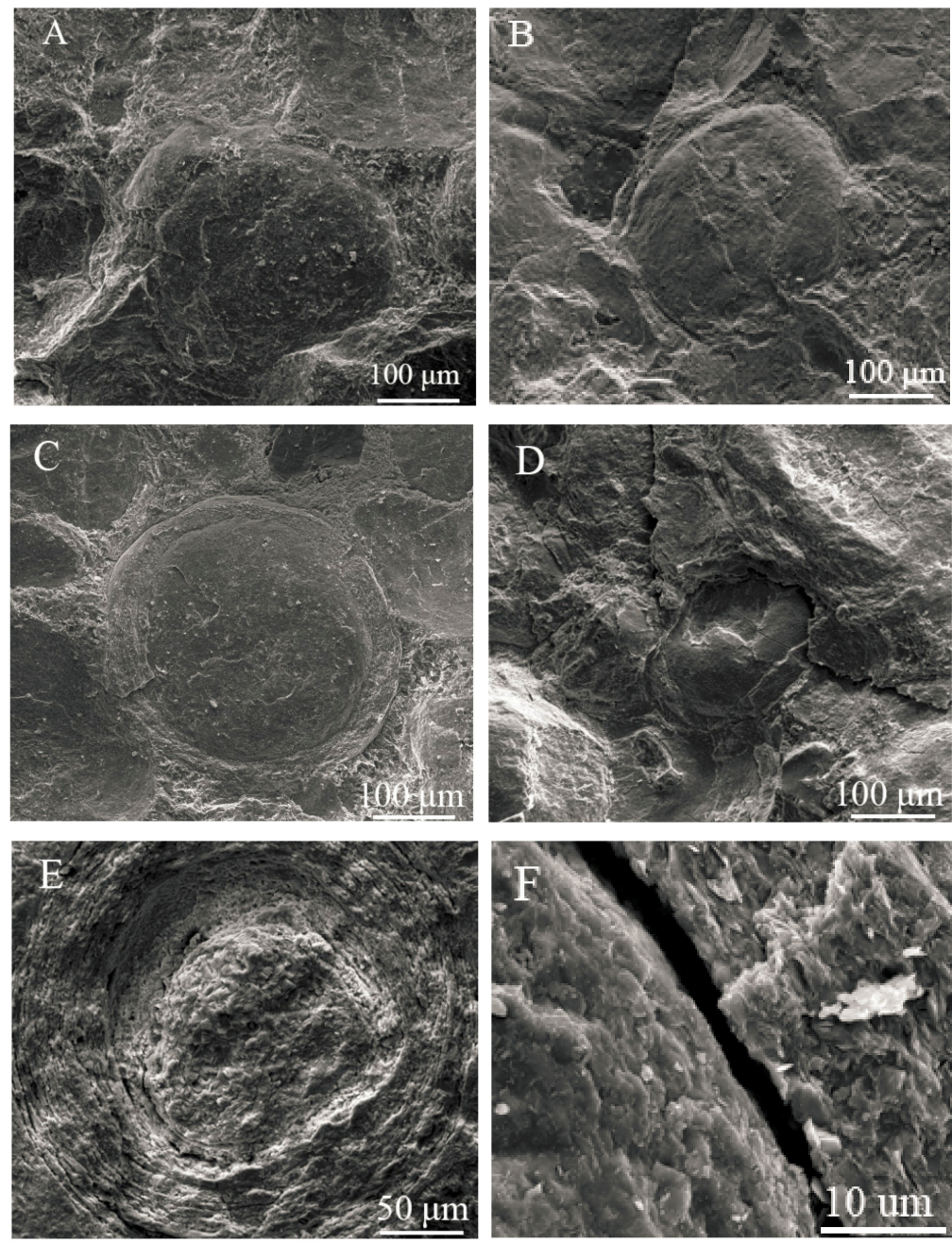

Figure 3. SEM images for different microwave processing conditions. (A) No treatment; (B) $1.5 \mathrm{~kW}, 45 \mathrm{~s}$; (C) $2 \mathrm{~kW}, 45 \mathrm{~s}$; (D) $2 \mathrm{~kW}, 60 \mathrm{~s}$; (E) $2.5 \mathrm{~kW}, 45 \mathrm{~s}$; (F) fraction enlargement of (E). 
Figure 4 shows the -0.038 -mm percentage of grinding product at a microwave power $2.5 \mathrm{~kW}$ for different microwave processing times. From Figure 2, it can be seen that the $-0.038-\mathrm{mm}$ percentage of grinding product increased significantly with increasing microwave processing time. When the microwave processing time was $45 \mathrm{~s}$, the -0.038 - $\mathrm{mm}$ percentage of grinding product increased by $31.7 \%$ compared to no microwave processing. However, when the microwave processing time was over $60 \mathrm{~s}$, the -0.038 -mm percentage of grinding product dropped significantly. The results indicated that microwave processing can significantly improve the grinding efficiency of oolitic hematite when the microwave processing time was less than $45 \mathrm{~s}$. However, when the microwave processing time was over $45 \mathrm{~s}$, increasing time had a negative effect on the improvement of grinding efficiency.

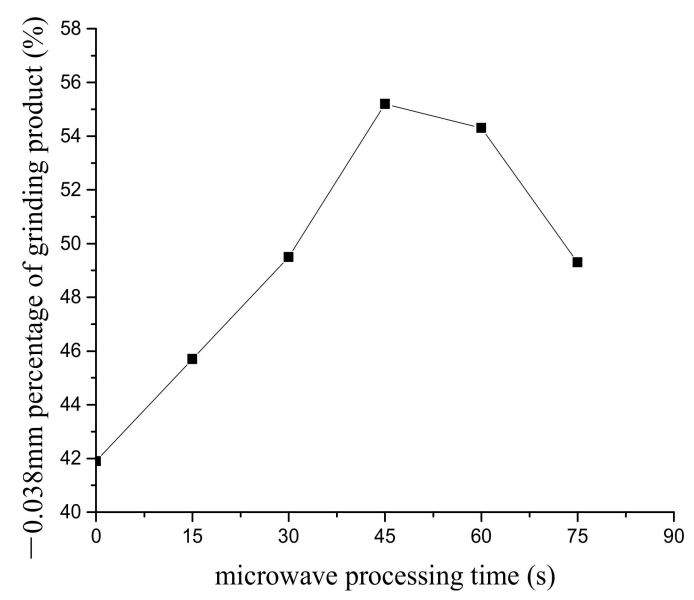

Figure 4. The -0.038 - $\mathrm{mm}$ percentage of the grinding product at a microwave power of $2.5 \mathrm{~kW}$ for different microwave processing time.

When the microwave processing time was less than $45 \mathrm{~s}$, the heat exchange was weak between iron minerals and gangues and hematite and gangues have different abilities to absorb microwave energy; therefore, the temperature difference between hematite and gangues increased with increasing microwave processing time. A larger temperature difference caused hematite to expand much more than gangues and generated thermal stress; therefore, grain boundary fractures were formed. When the microwave processing time was over $45 \mathrm{~s}$, the temperature of the inner oolitic hematite reached $550{ }^{\circ} \mathrm{C}$. Differential scanning calorimetry and thermogravimetric curves of oolitic hematite indicated that fine particles appeared melted and sintered (Figure 5). The melting and sintering of fine particles made the strength of oolitic hematite increase; therefore, the -0.038 - $\mathrm{mm}$ percentage of grinding product began to decrease.

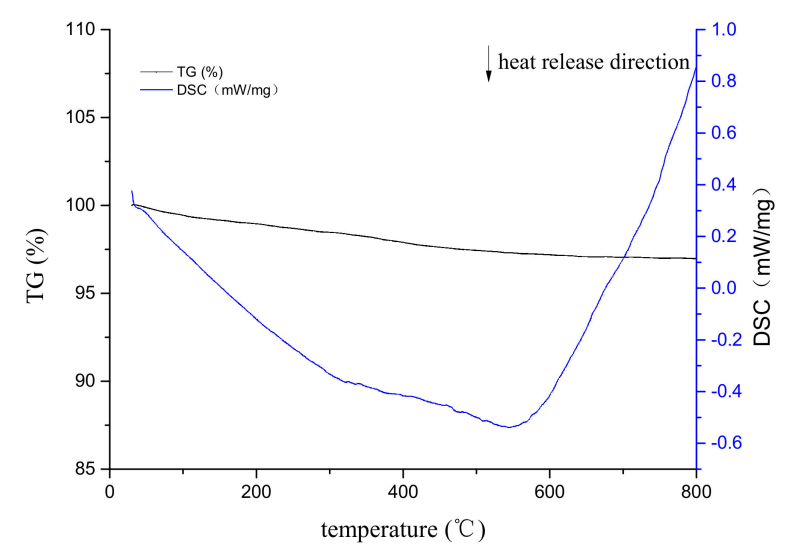

Figure 5. Differential scanning calorimetry and thermogravimetric curve of oolitic hematite. 
Figure 6 shows the -0.038 -mm percentage of grinding product at a microwave processing time $45 \mathrm{~s}$ for different microwave powers. It can be seen that the -0.038 - $\mathrm{mm}$ percentage of grinding product increased with the increasing microwave power and tended to be steady after $2.5 \mathrm{~kW}$. When the microwave power was $2.5 \mathrm{~kW}$, the -0.038 - $\mathrm{mm}$ percentage of grinding product increased by $31.7 \%$ in comparison with direct grinding.

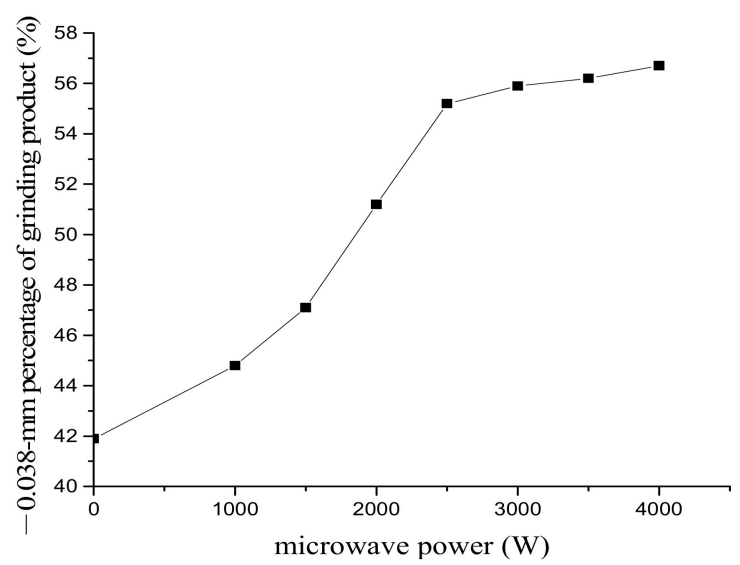

Figure 6. The -0.038 -mm percentage of grinding product at different microwave powers for $45 \mathrm{~s}$.

Because the per unit mass of the ore absorbed more energy with the increasing microwave power, this resulted in a greater temperature difference between hematite and gangues and formed greater thermal stress. Therefore, more intergranular fractures were generated, which led to the grindability of oolitic hematite to increase. However, the mass of ore limited the utilization of the microwave energy; when the microwave power was more than $2.5 \mathrm{~kW}$, the same mass of ore cannot absorb more energy at the same time, and therefore, the utilization of the microwave energy would be reduced. These inferences can be seen in Figure 7. The mass of the sample limited the utilization of microwave energy, and therefore, the heating rate of the sample was reduced when the mass of the sample was over $100 \mathrm{~g}$. When the microwave power was $2.5 \mathrm{~kW}$, the suitable mass of the sample was $100 \mathrm{~g}$. When the mass of the sample was over $100 \mathrm{~g}$ or less than $100 \mathrm{~g}$, the heating rate of the sample or the utilization of microwaves would reduce at a microwave power of $2.5 \mathrm{~kW}$.

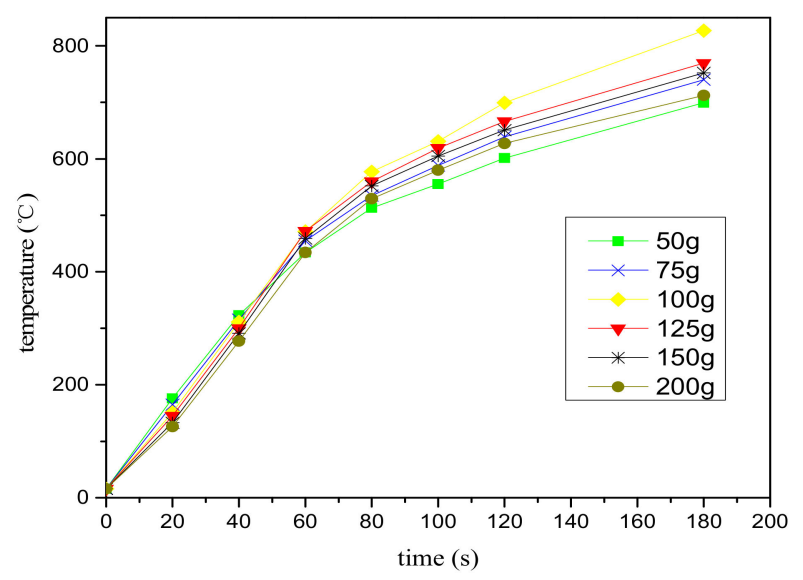

Figure 7. Heating curve of different masses of samples at a microwave power of $2.5 \mathrm{~kW}$.

\subsection{The Effect of Acid Leaching on Grinding}

Figure 8 shows the $-0.038-\mathrm{mm}$ percentage of grinding product at different acid dosages. The results indicated that the -0.038 - $\mathrm{mm}$ percentage of grinding product increased first and then 
decreased; and the dephosphorization ratio increased first and then became steady with the increasing acid dosage. When the acid dosage was $5 \%$, the -0.038 -mm percentage of grinding product, becoming the largest, was $63.3 \%$, and the dephosphorization ratio was $47.2 \%$.

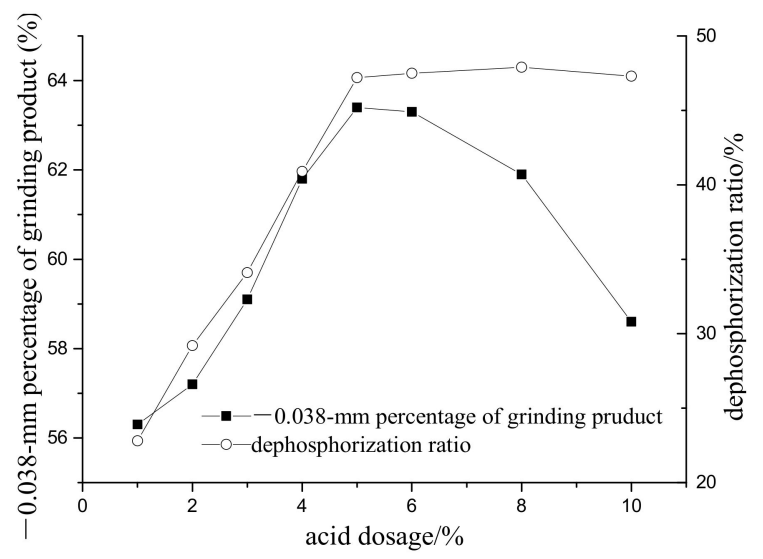

Figure 8. The -0.038 -mm percentage of grinding product and the dephosphorization ratio at different acid dosages.

In Figure 9, the XRD result showed that the carbonate-hydroxyapatite diffraction peak of ore weakened or disappeared in the grinding product after acid leaching. The reason was that hydrochloric acid reacted with carbonate-hydroxyapatite and made carbonate-hydroxyapatite dissolve; therefore, the content of phosphorus reduced in the grinding product. When the acid dosage was less than $5 \%$, the pulp viscosity gradually decreased with increasing acid dosage (Figure 10), which made it easier for hydrochloric acid to erode grain boundary fractures and made them extend and widen. This further decreased the mechanical strength of the ore, and the liberation of hematite increased, as well as the size of the grain reduced; therefore, the ore's grindability increased. In addition, hydrochloric acid can react with carbonate-hydroxyapatite to make phosphate mineral dissolve and transfer to solutions. Therefore, the -0.038 -mm percentage of the grinding product and the dephosphorization ratio increased. When the acid dosage was more than $5 \%$, the pulp viscosity began to increase (Figure 10), and it was not beneficial for the acid to enter the grain boundary fractures, so the mechanical strength of the ore increased compared to the ore treated by an acid dosage of $5 \%$; therefore, the -0.038 -mm percentage of the grinding product began to decrease. Although there more hydrochloric acid could be introduced to the reaction, the reaction point of carbonate-hydroxyapatite was limited, so increasing the acid dosage, the degree of reaction was the same; therefore, the dephosphorization ratio became steady.

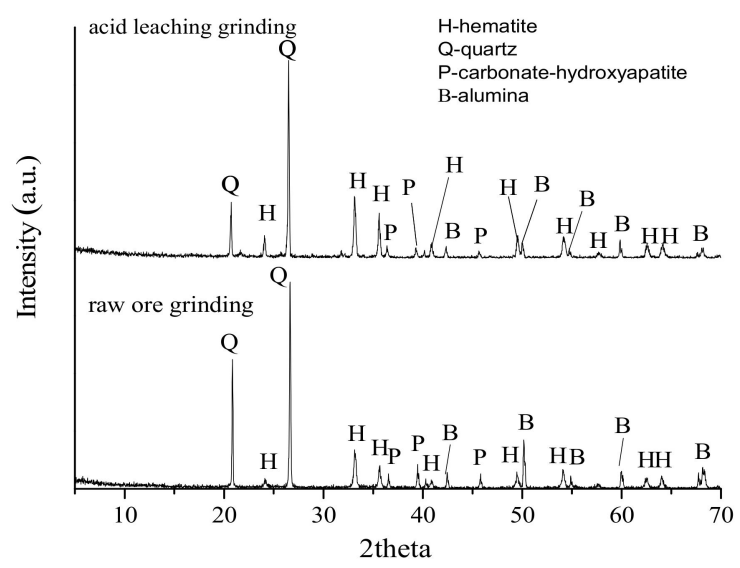

Figure 9. XRD pattern of the acid leached grinding product and direct grinding product. 


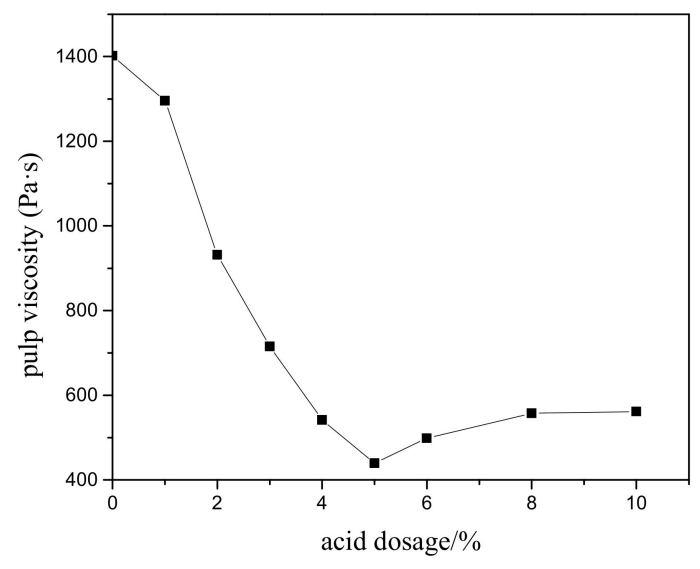

Figure 10. Pulp viscosity of different acid dosages.

Figure 11 shows the -0.038 -mm percentage of grinding product at different acid leaching times. The results showed that the -0.038 -mm percentage of grinding product and the dephosphorization ratio increased first and then became steady.

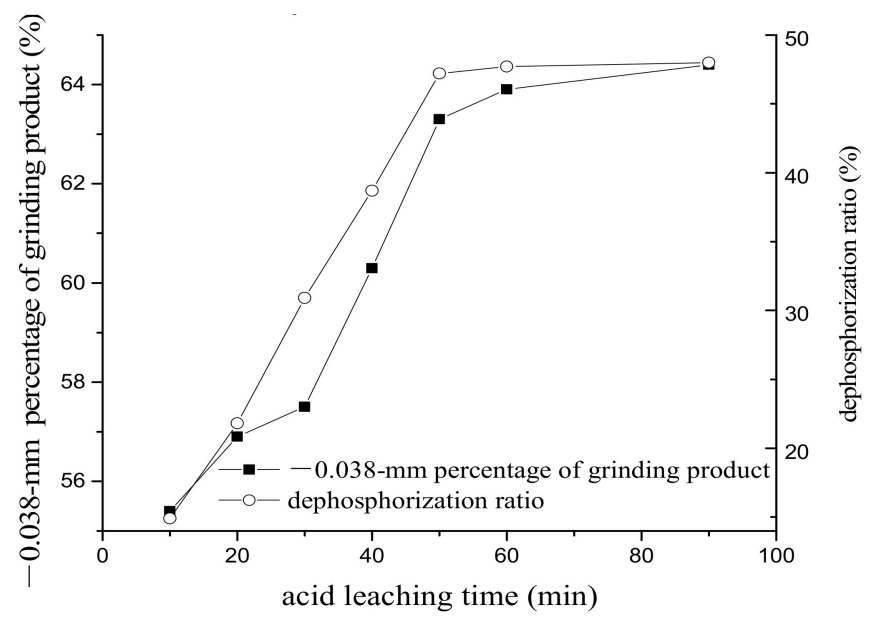

Figure 11. The $-0.038-\mathrm{mm}$ percentage of the grinding product and the dephosphorization ratio at different acid leaching times.

When acid leaching time was less than $50 \mathrm{~min}$, the erosion of hydrochloric acid of grain boundary fractures increased with the increasing acid leaching time. This made the mechanical strength of the ores decrease; therefore, the $-0.038-\mathrm{mm}$ percentage of the grinding product gradually increased. When the acid leaching time was $50 \mathrm{~min}$, the reaction between hydrochloric acid and carbonate-hydroxyapatite reached a balance, and the erosion of hydrochloric acid of grain boundary fractures was the most weak. The mechanical strength of the ore would not change with increasing acid treatment time; therefore, the -0.038 - $\mathrm{mm}$ percentage of the grinding product and the dephosphorization ratio became steady.

\subsection{Liberation Analysis}

Figure 12 shows the liberation of different grinding products. The results indicated that the hematite liberation by microwave processing of the grinding product increased by $34.92 \%$, and especially, the fractions of $-0.038-\mathrm{mm}$ and $0.05-0.074 \mathrm{~mm}$ increased by $30.11 \%$ and $74.50 \%$, respectively, in comparison with direct grinding. The acid leached grinding product increased by $54.80 \%$, and especially, the fractions of $-0.038-\mathrm{mm}$ and $0.05-0.074 \mathrm{~mm}$ increased by $47.74 \%$ and 
$114.50 \%$, respectively, in comparison with direct grinding. The hematite liberation of the fractions of $-0.038-\mathrm{mm}$ and $0.05-0.074 \mathrm{~mm}$ increased significantly, but there was no obvious change in other grain sizes. This indicated that oolitic hematite generated selective liberation in the grinding process after microwave processing, and acid leaching further accelerated the improvement of the selective liberation. Therefore, microwave processing and acid leaching comprised an efficient method to improve the hematite liberation.

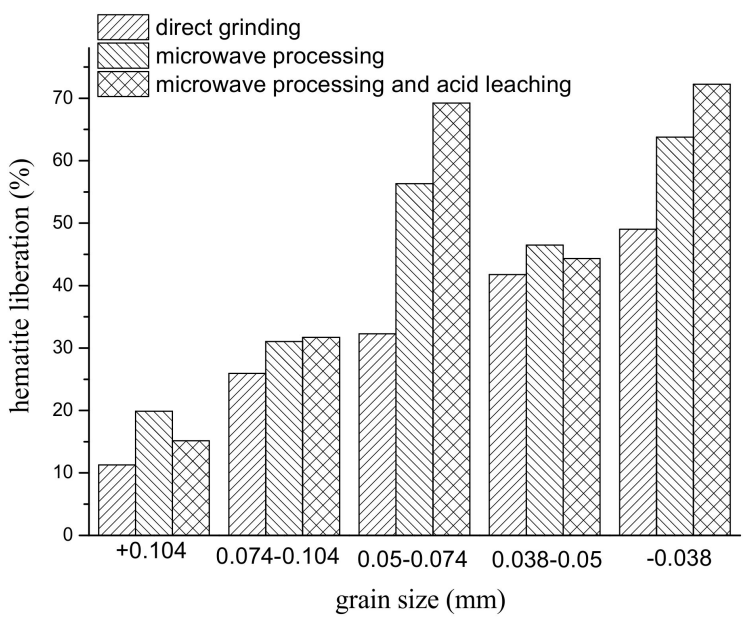

Figure 12. Hematite liberation of three respective samples grinding products with different grain size ranges.

\subsection{Magnetic Separation Results Analysis}

Figure 13 shows that after microwave processing, the iron grade, recovery of iron and dephosphorization ratio of magnetic separation product increased by $5.65 \%, 17.99 \%$ and $3.27 \%$, respectively, in comparison with direct grinding. After microwave processing and acid leaching, the iron grade, recovery of iron and dephosphorization ratio of the magnetic separation product increased by $14.26 \%$, $34.62 \%$ and $43.49 \%$, respectively, in comparison with direct grinding. The results indicated that after microwave processing and acid leaching, the efficiency of magnetic separation improved significantly, and acid leaching made the dephosphorization ratio increase significantly. This was because the hematite liberation increased after microwave processing and acid leaching, and hydrochloric acid could react with carbonate-hydroxylapatite to cause the content of phosphorus reduce. These results were in good agreement with the grinding and liberation results mentioned before.

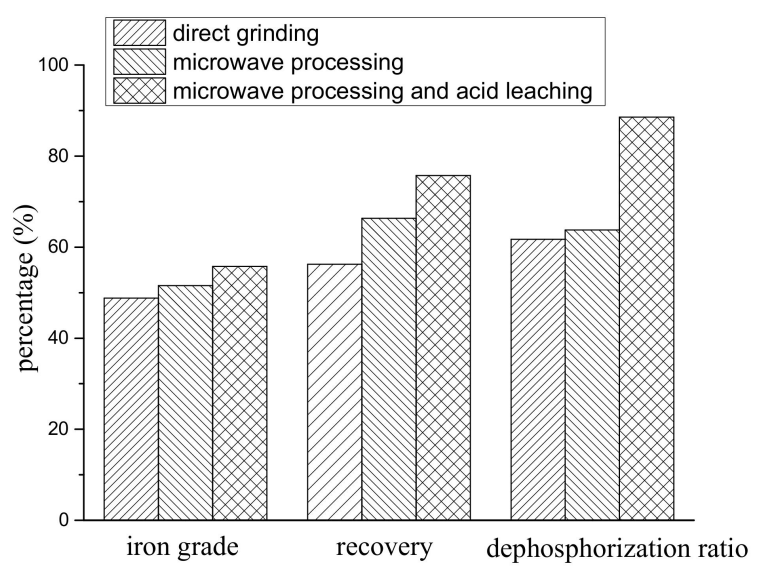

Figure 13. Iron grade, recovery and dephosphorization of the magnetic separation product of three samples. 


\subsection{Error Analysis}

In grinding processing, the absolute error of the -0.038 - $\mathrm{mm}$ percentage of the grinding product was $0.25 \%$, and the minimum change of the $-0.038-\mathrm{mm}$ percentage of the grinding product was $5.2 \%$ compared to direct grinding. Therefore, the largest relative error of the -0.038 - $\mathrm{mm}$ percentage of the grinding product was $4.8 \%$. Therefore, the result of the $-0.038-\mathrm{mm}$ percentage of the grinding product was reliable. For liberation, the absolute error of liberation was $0.75 \%$, and the minimum change of liberation was $13.57 \%$; therefore, the largest relative error of liberation was $5.5 \%$. Therefore, the result of the liberation is reliable. In magnetic separation, the absolute error of iron grade, recovery and dephosphorization ratio were $0.15 \%, 0.2 \%$ and $0.15 \%$, respectively. The minimum change of the iron grade was $2.76 \%$; therefore, the largest relative error of the iron grade was $5.4 \%$. The minimum change of recovery was $10.12 \%$; therefore, the largest relative error of recovery was $2.0 \%$. The change of the dephosphorization ratio is $26.85 \%$; therefore, the relative error of the dephosphorization ratio was $0.6 \%$. Therefore, the result of magnetic separation was reliable.

\section{Conclusions}

From the results of this investigation, the following conclusions can be drawn:

(1) Microwave processing is able to make this ore be selectively liberated in the grinding process, and acid leaching further improves the selective liberation and reduces the content of phosphorus in the grinding product.

(2) Excessive microwave processing treatment has a negative effect on the liberation of ores. Excessive acid dosage is not beneficial to the improvement of selective liberation and the dephosphorization ratio.

(3) Microwave processing and acid leaching comprise an efficient and feasible method to liberate high-phosphorus oolitic hematite.

(4) Microwave processing and acid leaching can improve magnetic separation products' indexes significantly.

Author Contributions: X.C. and G.Q. conceived of and designed the experiments. X.C., B.Z. and Q.C. performed the experiments. X.C. and C.H. analyzed the data. G.Q. contributed reagents, materials and tools. X.C. wrote the paper.

Funding: The work was supported by the "Eleventh Five-Year" National Science and Technology Support Program-funded projects (2007BAB15B01).

Acknowledgments: Review of the draft paper by Gongming Qian, Wuhan University of Science and Technology, is gratefully acknowledged. Review and comments from the anonymous reviewers are also greatly appreciated.

Conflicts of Interest: The authors declare no conflict of interest.

\section{References}

1. Sun, B. Progress in China's Beneficiation Technology for Complex Refractory Iron Ore. Met. Mine 2006, 3, $11-13$.

2. Wu, J.; Wen, Z.; Cen, M. Development of Technologies for High Phosphorus Oolitic Hematite Utilization. Steel Res. Int. 2011, 82, 494-500. [CrossRef]

3. Zhang, J.; Hu, L.; Liang, Y.; Yang, H.; Sun, D. The research on refractory oolitic hematite and expectation. China Min. Mag. 2007, 16, 74-76.

4. Xu, C.; Sun, T.; Kou, J.; Li, Y.; Mo, X.; Tang, L. Mechanism of phosphorus removal in beneficiation of high phosphorous oolitic hematite by direct reduction roasting with dephosphorization agent. Trans. Nonferr. Met. Soc. China 2012, 22, 2806-2812. [CrossRef]

5. Dai, H.; Zhao, W.; Gao, L.; Song, B. Process Mineralogy of an Oolitic Hematite Ore and its Implications for Mineral Processing. Adv. Mater. Res. 2012, 567, 131-134. [CrossRef] 
6. Ueda, T.; Oki, T.; Koyanaka, S. A general quantification method for addressing stereological bias in mineral liberation assessment in terms of volume fraction and size of mineral phase. Miner. Eng. 2018, 119, 156-165. [CrossRef]

7. Mariano, R.A.; Evans, E.L.; Manlapig, E. Definition of random and non-random breakage in mineral liberation-A review. Miner. Eng. 2016, 94, 51-60. [CrossRef]

8. Veasey, T.J.; Wills, B.A. Review of methods of improving mineral liberation. Miner. Eng. 1991, 4, 747-752. [CrossRef]

9. Little, L.; Mainza, A.N.; Becker, M.; Wiese, J.G. Using mineralogical and particle shape analysis to investigate enhanced mineral liberation through phase boundary fracture. Powder Technol. 2016, 301, 794-804. [CrossRef]

10. Fandrich, R.G.; Bearman, R.A.; Boland, J.; Lim, W. Mineral liberation by particle bed breakage. Miner. Eng. 1997, 10, 175-187. [CrossRef]

11. Wang, E.; Shi, F.; Manlapig, E. Mineral liberation by high voltage pulses and conventional comminution with same specific energy levels. Miner. Eng. 2012, 27-28, 28-36. [CrossRef]

12. Jones, D.A.; Lelyveld, T.D.; Mavrofidis, S.D.; Kingman, S.W.; Miles, N.J. Microwave heating applications in environmental engineering-A review. Resour. Conserv. Recycl. 2002, 34, 75-90. [CrossRef]

13. Chen, G.; Chen, J.; Guo, S.; Li, J.; Srinivasakannan, C.; Peng, J. Dissociation behavior and structural of ilmenite ore by microwave irradiation. Appl. Surf. Sci. 1990, 258, 4826-4829. [CrossRef]

14. Sahoo, B.K.; De, S.; Carsky, M.; Meikap, B.C. Rheological characteristics of coal-water slurry using microwave pretreatment-A statistical approach. J. Ind. Eng. Chem. 2011, 17, 62-70. [CrossRef]

15. Scott, G.; Bradshaw, S.M.; Eksteen, J.J. The effect of microwave pretreatment on the liberation of a copper carbonatite ore after milling. Int. J. Miner. Process. 2008, 85, 121-128. [CrossRef]

16. Amankwah, R.K.; Khan, A.U.; Pickles, C.A.; Yen, W.T. Improved grindability and gold liberation by microwave pretreatment of a free-milling gold ore. Miner. Process. Extr. Metall. 2005, 114, 30-36. [CrossRef]

17. Song, S.; Campos-Toro, E.F.; Valdivieso, A.L. Formation of microfractures on an oolitic iron ore under microwave treatment and its effect on selective fragmentation. Powder Technol. 2013, 243, 155-160. [CrossRef]

18. Fitzgibbon, K.E.; Veasey, T.J. Thermally assisted liberation-A review. Miner. Eng. 1990, 3, 181-185. [CrossRef]

19. Jones, D.A.; Kingman, S.W.; Whittles, D.N.; Lowndes, I.S. Understanding microwave assisted breakage. Miner. Eng. 2005, 18, 659-669. [CrossRef]

20. Gu, S.; Chen, G.; Peng, J.; Chen, J.; Li, D.; Liu, L. Microwave assisted grinding of ilmenite ore. Trans. Nonferr. Met. Soc. China 2011, 21, 2122-2126. [CrossRef]

21. Walkiewicz, J.W.; Clark, A.E.; McGill, S.L. Microwave-assisted grinding. IEEE Trans. Ind. Appl. 1991, 27, 239-243. [CrossRef]

22. Omran, M.; Fabritius, T.; Mattila, R. Thermally assisted liberation of high phosphorus oolitic iron ore: A comparison between microwave and conventional furnaces. Powder Technol. 2015, 269, 7-14. [CrossRef]

23. He, Z.; Zhang, H.; Jin, Y. Mechanism Study on the High-phosphorus Hematite Carbothermal Reduction in Microwave Field. Adv. Mater. Res. 2011, 291-294, 1358-1361. [CrossRef]

24. Omran, M.; Fabritius, T.; Mattila, R.; Abdel-Khalek, N.; Gornostayev, S. Improvement of phosphorus removal from iron ore using combined microwave pretreatment and ultrasonic treatment. Sep. Purif. Technol. 2015, 156, 724-737. [CrossRef]

25. Zhong, L.; Gong, W.; Li, Y.; Xin, Z.; Lu, Y.; Liu, S. Experimental study on acid leaching intensified by ultrasonic wave to remove phosphorus from high-phosphorus iron ore. J. Wuhan Univ. Technol. 2012, 34, 107-110.

26. Deniz, V.; Ozdag, H. A new approach to Bond grindability and work index: Dynamic elastic parameters. Miner. Eng. 2003, 16, 211-217. [CrossRef]

(C) 2018 by the authors. Licensee MDPI, Basel, Switzerland. This article is an open access article distributed under the terms and conditions of the Creative Commons Attribution (CC BY) license (http://creativecommons.org/licenses/by/4.0/). 